\title{
Perinatal Brain Damage Causation
}

\author{
Olaf Dammann ${ }^{a, b, c} \quad$ Alan Leviton $^{\mathrm{b}}$ \\ aperinatal Infectious Disease Epidemiology Unit, OE 6415, Hannover Medical School, Hannover, Germany; \\ ${ }^{b}$ Neuroepidemiology Unit, Children's Hospital, and ' Division of Newborn Medicine, Floating Hospital for \\ Children at Tufts-New England Medical Center, Boston, Mass., USA
}

\section{Key Words}

Brain damage $\cdot$ Fetus $\cdot$ Immature brain $\cdot$ Neonatal brain injury $\cdot$ Perinatal brain $\cdot$ Causation $\cdot$ Causal inference

\begin{abstract}
The search for causes of perinatal brain damage needs a solid theoretical foundation. Current theory apparently does not offer a unanimously accepted view of what constitutes a cause, and how it can be identified. We discuss nine potential theoretical misconceptions: (1) too narrow a view of what is a cause (causal production vs. facilitation), (2) extrapolating from possibility to fact (potential vs. factual causation), (3) if $X$, then invariably $Y$ (determinism vs. probabilism), (4) co-occurrence in individuals vs. association in populations, (5) one cause is all that is needed (single cause attribution vs. multicausal constellations), (6) drawing causal inferences from very small numbers of observations (the tendency to generalize), (7) unstated causal inferences, (8) ignoring heterogeneity, and (9) failing to consider alternative explanations for what is observed. We hope that our critical discussion will contribute to fruitful research and help reduce the burden of perinatal brain damage.
\end{abstract}

Copyright $\odot 2007$ S. Karger AG, Basel

\section{Introduction}

The heterogeneous spectrum of perinatal brain damage $(\mathrm{PBD})$ in term and preterm infants warrants a detailed consideration of the equally heterogeneous spectrum of causes of PBD. For identification of preventive measures, detailed knowledge about pathogenesis and etiology is paramount. However, before candidate causes can be identified, the causative framework, i.e. the concept of PBD causation in general, deserves consideration.

In this article, we do not offer an exhaustive overview of the various clinical and imaging characteristics of $\mathrm{PBD}$, which is provided in several recent reviews [1-3]. Instead, we expand upon recent reviews of PBD etiology and pathogenesis [4-6] with an eye on causal inference, writing from the perinatal neuroepidemiologists' perspective.

\section{Causal Inference and a Neopragmatic View of Etiology Research}

Modern etiology research in humans needs to be based on sound empirical methods [7]. This type of research relies on the observation of associations between exposures and outcomes, usually in humans, with the goal of identifying preventable causes of disease. On the other hand, we are all too familiar with the notion that 'association can never prove causation'. This notion has two components in the present context - the general problem of proof by observation, and the specific problem of how to define causes in empirical etiology research.

The general problem has been formulated by David Hume (1711-1776), who claimed that multiple observations of similar co-occurrences do not justify any (inductive) conclusions beyond just these observations. This concept was extended by Sir Karl Popper (1902-1994)

\section{KARGER}

๑ 2007 S. Karger AG, Basel

Fax +41613061234

E-Mail karger@karger.ch

www.karger.com
Accessible online at: www.karger.com/dne
Olaf Dammann, Dr. med, S.M.

Director of Clinical Research, Division of Newborn Medicine Department of Pediatrics, Tufts-New England Medical Center 750 Washington St., Boston, MA 02111 (USA)

Tel. +1 617636 0240, Fax +1 617636 8943, E-Mail ODammann@tufts-nemc.org 
who offered his 'falsificationist' approach, which states that no number of similar observations can prove a hypothesis, while just one dissimilar observation can refute the conjecture - a theory perceived and discussed in both, statistics [8] and epidemiology [9-11]. An overview of the more recent philosophical discourse on causality $[12,13]$ is far beyond the scope of this paper.

The specific problem, i.e. how to conceptualize (and compute) 'causation', is far from simple and has produced a vast theoretical literature in the fields of epidemiology [14-18] and computer science [19,20]. According to what is probably the most widely-known view in the epidemiologic literature $[18,21]$, we should move from looking at individual component causes of disease, i.e. pieces of the pie, towards the appreciation of causal constellations, i.e. the entire pie. Only when the pie is complete will disease follow. This view might be considered inherently deterministic, because it holds that whenever the causal constellation is complete, disease follows inevitably. However, even in light of considerable progress in molecular epidemiology [22], and even if we supplement epidemiology with appropriate experimental work, we are unlikely to discover the entire causal constellation in humans just by observation. 'Even the most careful and detailed mechanistic dissection of individual events cannot provide more than associations, albeit at a finer level' [18].

Thus, in practice, all etiology research can provide seems to be restricted to an approximation of 'real' causes via the identification of risk factors. In theory, researchers may wish to fix the deterministic pie problem above by 'simply think(ing) of the components as contributing together to the probability of the effect, rather than being sufficient for it' [17].

Could it thus be that finding 'real' causes of disease will remain elusive, because the question is ill posed? Indeed, some current thinking suggests we should stop 'describing (human inquiry) as an attempt to correspond to the intrinsic nature of reality (and start) describing it as an attempt to serve transitory purposes and solve transitory problems' [23]. The major proponent of what is sometimes called 'neopragmatism' is Richard Rorty, selfdeclared 'anti-dualist', who suggests that Platonic-Cartesian notions of 'the absolute and the relative, the found and the made, object and subject, nature and convention, reality and appearance' should be replaced with 'new ways of speaking'. Rorty suggests we should 'develop tools which will enable (humans) to enjoy more pleasure and less pain'. Along these very lines, could not we just stop taking 'causal relationships to be the fundamental building blocks both of physical reality and of human understanding of that reality' $[19, \mathrm{p}$. xiii/xiv] and start accepting observed associations, supplemented with some experimental evidence, as a sufficient starting point for change? Even if this was just changing language instead of solving a pressing philosophical problem, would not the ends (improved public health) justify the means (ignoring Hume, plus dropping the dualistic worldview)?

In essence, we suggest that it does not matter whether we call an observed link between exposure and outcome 'causation' or 'association'. What does matter is that identifying risk factors for disease, and then proactively removing/reducing the identified risk factors from populations can improve the human condition.

Clinical investigators are reluctant to expose human subjects to interventions that do not have a sound basic science rationale. To aid in the process of selecting risk factors for avoidance/modification, in the final section of this paper we offer criteria for what is worthy of evaluation. These should not be viewed as criteria for causes of disease.

\section{Causal Concepts in PBD}

Consider two scenarios. In the first, short-term intrapartum and neonatal insults are considered sufficient to damage the neonatal brain [24-26]. In the second, longstanding antenatal exposures are recognized as potentially changing the milieu in the fetal central nervous system, thereby playing a causative role in PBD [27-32]. In both scenarios, however, it might be helpful to integrate endogenous (e.g. maturation-related anatomic and/or physiologic/genetic) factors with exogenous (e.g. insult/ milieu-related) phenomena, such as energy failure and/or inflammation [33].

Moreover, the two scenarios differ with regard to what qualifies as an insult or harmful milieu. While maturational factors (for which gestational age is a surrogate [34]) clearly contribute to PBD occurrence, circulatory and inflammatory risk factors are currently among the most frequently studied. Unfortunately, this recent development is frequently misinterpreted as an attempt to replace one 'old' cause with a 'new' one. This perception, however, neglects the potential advantages of multiple cause appreciation, most importantly: an increase in the number of potential prevention opportunities.

A misperception of what constitutes a causal relationship appears to contribute to this misunderstanding. Although the issues discussed in this paper apply to a large extent to disease causation in general, our area of 
Table 1. Nine conceptual problems in causation thinking, common assumptions associated with these, and proposals how to avoid causal misattribution

\begin{tabular}{|c|c|c|c|}
\hline No. & Conceptual problem & Assumption & Proposal \\
\hline 1 & $\begin{array}{l}\text { Causal production vs. causal } \\
\text { facilitation }\end{array}$ & $\mathrm{X}$ is cause of $\mathrm{Y}$ only if $\mathrm{X}$ produces $\mathrm{Y}$ & $\begin{array}{l}\mathrm{X} \text { is cause of } \mathrm{Y} \text { if } \mathrm{X} \text { contributes to the occur- } \\
\text { rence of } \mathrm{Y} \text {, even if other exposures are required }\end{array}$ \\
\hline 2 & $\begin{array}{l}\text { Potential vs. factual causation } \\
\text { (extrapolating from possibility to fact) }\end{array}$ & $\begin{array}{l}\text { If } \mathrm{X} \text { can cause } \mathrm{Y} \text { (e.g. in experiments), } \\
\text { then } \mathrm{X} \text { does cause } \mathrm{Y} \text { in real life }\end{array}$ & If $\mathrm{X} \underline{\text { can }}$ cause $\mathrm{Y}$, then $\mathrm{X} \underline{\text { might }}$ cause $\mathrm{Y}$ \\
\hline 3 & Determinism vs. probabilism & If $\mathrm{X}$ then always $\mathrm{Y}$ & If $\mathrm{X}$ then $\mathrm{Y}$ more frequently than if not $\mathrm{X}$ \\
\hline 5 & $\begin{array}{l}\text { Single cause attribution vs. multicausal } \\
\text { constellations }\end{array}$ & $\mathrm{Y}$ is caused only by $\mathrm{X}$ & $\begin{array}{l}\text { Y has many causes, including } \mathrm{X} \text {, even in any } \\
\text { individual }\end{array}$ \\
\hline 6 & Generalization & $\begin{array}{l}\text { If } \mathrm{X} \text { is a cause of } \mathrm{Y} \text { in one instant, } \\
\mathrm{X} \text { is always a cause of } \mathrm{Y}\end{array}$ & $\begin{array}{l}\text { If } \mathrm{X} \text { is a cause of } \mathrm{Y} \text { in one instant, } \mathrm{X} \text { can be a } \\
\text { cause of } \mathrm{Y}\end{array}$ \\
\hline 8 & Ignoring heterogeneity & $\begin{array}{l}\text { If } \mathrm{X} 1 \text { is similar to } \mathrm{X} 2 \text {, they can be } \\
\text { combined as one }\end{array}$ & $\begin{array}{l}\text { If } \mathrm{X} 1 \text { is similar to } \mathrm{X} 2 \text {, evaluate similarity before } \\
\text { combining }\end{array}$ \\
\hline 9 & Failure to consider alternatives & What I see is true & $\begin{array}{l}\text { Consider that what is seen can be explained } \\
\text { away and is not what it appears to be }\end{array}$ \\
\hline
\end{tabular}

In this table, $\mathrm{X}$ is an exposure or characteristic and $\mathrm{Y}$ and $\mathrm{Z}$ are disorders of interest.

concern is $\mathrm{PBD}$ causation. In particular, we are interested in white matter damage (WMD), the term we use for focal and diffuse structural damage to the paraventricular white matter identified mainly in preterm newborns [35].

\section{Nine Misconceptions in PBD Causation Thinking}

We wrote this essay to raise awareness about issues that epidemiologists take for granted but others might not appreciate. We very much want to avoid embarrassing anyone who might have expressed any of these misconceptions. Thus, we have minimized identifying papers that exemplify the very conceptual lapses we want the reader to recognize and avoid.

In the following sections, we expand on each of these nine issues. Because replacing some of what we consider misconceptions with new perspectives can be difficult, we created the table (table 1) to aid in this process. We end this paper by offering some conclusions based on our discussion.

\section{Causal Production vs. Causal Facilitation}

We consider too simplistic the view that some factor is a cause only if it produces disease. A more appropriate view might be that a factor is considered a cause when it contributes to disease occurrence, either by producing it or by facilitating its production by other causes.

Some exposures by themselves do not influence the risk of a disease. In the presence of other exposures, however, they enhance the occurrence of disease. More commonly, the exposure has a small influence in isolation, but in the presence of another exposure, has a greater than additive effect. This concept of 'sensitization' [36] is exemplified by the observation that the extent of cerebral infarction in 7-day old rats is greater following the combination of a low dose of endotoxin and a short period of hypoxia-ischemia than by either exposure alone [37]. Similarly, exposure to proinflammatory cytokines increases ibotenate-iduced excitotoxic cortical and WMD in a murine preterm model [38].

On the epidemiologic level, this phenomenon is called 'effect modification', and under particular circumstances we may face effect modifiers that are themselves not pro- 
ducers of disease. For example, in one of our recent studies we looked at the risk of WMD after exposure to hypocarbia [39]. In these analyses, maternal antibiotic therapy was associated with neither hypocarbia nor WMD. However, among children whose mothers had received antibiotic treatment, the adjusted odds ratio for hypocarbia predicting WMD was 0.9 (95\% confidence interval 0.32.9), while it was 2.7 (1.1-6.6) among infants whose mothers had not received antibiotic therapy. Clearly, although not associated with WMD in the first place, maternal antibiotic therapy was associated with WMD occurrence by virtue of conveying information about modifying the effect of hypocarbia (or its antecedents or correlates) on WMD risk.

One (neopragmatic) way to avoid the failure to recognize causal facilitation is to enhance our etiologic lexicon by using terms such as 'contributor' or 'risk factor' a bit more frequently. Then we can talk about phenomena that contribute to disease, and not have confusion about what constitutes a cause.

\section{Potential vs. Factual Cause}

We sometimes fall into the trap of what might be called 'extrapolation from possibility to fact'. By this we mean that some tend to think that if $\mathrm{X}$ can cause $\mathrm{Y}$ in the experimental setting, $\mathrm{X}$ does cause $\mathrm{Y}$ in real-life situations. The experimental evidence from perinatal neuroscience that some exposures can result in WMD is large and continues to grow [4]. Such experimental evidence, however, shows only that these factors are candidate causes of WMD. We should not assume they are causes in humans.

Along these lines, the current assumption that WMD in immature human newborns is caused by hypoxia-ischemia is an extrapolation error, but not from possibility to fact, but from missing data. In essence, the inferential error has no basis in fact. In the article that coined the term 'periventricular leukomalacia', the authors considered the entity 'a neonatal form of anoxic encephalopathy' [40]. However, they did not offer any supporting evidence why anoxia should be the cause for the damage observed. Despite this lack of data, an article published in 2002 cited this paper this way, '[Banker and Larroche] found additional pathological changes within the lungs of all infants examined and noted that the majority had experienced a period of apnea or cardiac arrest requiring resuscitation. Anoxia was recorded as present without exception in every infant in their series' [25]. Although anoxia may have been recorded, it was not measured at all. The authors assumed anoxia was present because the infants had had trouble breathing or had experienced cardiac arrest. It might be of interest to clinicians responsible for keeping oxygen saturation values of preterm infants in the 'acceptable' range that multiple experimental studies support the claim that hypoxia without ischemia does not cause brain damage [41-43] and that ventilated preterm newborns are 'able to maintain adequate cerebral perfusion at a MABP in the range of $23.7-39.3 \mathrm{~mm}$ Hg' [44].

Until today, the anoxia/asphyxia/hypoxia-ischemia complex of putative causes has its accustomed place in the introductions of scientific articles and textbooks on preterm brain damage (see below, section 'Single Cause Attribution vs. Multicausal Constellations'), as well as in the courtroom. This is mainly because in response to such initial 'observations' of anoxia, a very successful rat model of hypoxia-ischemia has been developed $[43,45]$, modifications of which are probably among the most commonly used models of PBD. One should not cease asking the question how relevant hypoxia-ischemia is among term, and even more among preterm infants, for causation of PBD and other neonatal disorders such as necrotizing enterocolitis [46].

In sum, the evidence in the literature that hypoxiaischemia can indeed cause brain lesions is vast [26]. However, the inference that brain damage in human newborns must therefore be hypoxic-ischemic in origin is not well supported by solid observational evidence [47].

\section{Determinism vs. Probabilism}

Most people think of causation as an 'if, then' sequence of events. The generalized example is 'if X, then Y'. Now, the backbone of determinist thinking is the assumption that 'if X, then always Y'. For some phenomena, such as those well-described by natural laws, the determinist view might indeed apply. However, the applicability of natural laws to disease processes might be less common than frequently assumed.

The generalized form for the probabilistic approach to causation $[48,49]$ is 'if $X$, then the probability of $Y$ is increased'. Our inference is that when we see $\mathrm{X}$, we think that the occurrence of $\mathrm{Y}$ is more likely than if we do not see $\mathrm{X}$.

Infection with HIV is considered the cause of AIDS [50]. However, not all HIV-infections lead to the rapid development of the full-blown clinical syndrome called AIDS, as illustrated by the existence of highly exposed, persistently seronegative individuals and HIV-1-infected long-term nonprogressors [51]. Simply put, it is not yet known whether some of these individuals will ever de- 
velop signs of AIDS. To elucidate the protective characteristics among these few cases will greatly improve our understanding of AIDS pathogenesis and causation.

Along these same lines, some investigators might put too much deterministic emphasis on what they expect to follow a certain exposure. In one recent study, for example, investigators noted that almost half of their cases of WMD 'occurred unexpectedly in infants who did not appear to have an obvious cause, as they had not experienced a severe hemodynamic event' [52]. Apparently, some favor certainty over likelihood. We are confident that based on our discussion, at least some determinists will probably consider becoming determined probabilists (pun intended).

\section{Co-Occurrence in Individuals vs. Association in} Populations

Some tend to rely on anecdotal evidence even in an era when information about etiology comes from data derived from research in large groups of subjects. We, on the other hand, suggest that the evidence-based perspective [53] should not only be applied to therapy studies, but also to etiology research [54].

The emphasis on the individual is typically taken by clinicians interested in causation issues in individual patients. For example, a physician would never have the slightest doubt about the etiology of lung cancer in a heavy smoker, but would always wonder about its pathogenesis in a lifelong nonsmoker.

WMD is often seen in the sickest preterm newborns. In the same infants, the blood pressure tends to be on the low side. Does this mean that a low systemic blood pressure must be a cause for WMD? Indeed, the majority of studies of observational studies have not shown an association between measures of systemic blood flow and WMD [for an overview, see appendix of reference 55].

The concepts of co-occurrence and association are related, but by no means identical. Hybrid papers that mix the small- and large-sample perspectives have the potential to be confusing.

Association does not prove causation, as recently shown for the association between changes in regional stork populations and birth rates [56]. Similarly, the harmful effects of smoking are not supported by the observation that all smokers die, but by the observation that smoking increases the likelihood of lung cancer and/or death at an earlier age above what we know from populations of nonsmokers.

In keeping with this view, finding so-called 'proinflammatory' cytokines in areas of neonatal WMD does not mean that they contributed to the damage. Their pres- ence might also indicate that they are part of other responses to an injurious stimulus. For example, they might play a neuroprotective role, contribute to diminishing the inflammation, or participate in repair $[57,58]$.

\section{Single Cause Attribution vs. Multicausal}

Constellations

Imagine an elderly lady being hit by a bus. She breaks her leg. Although this has shown that bus accidents can cause broken legs, to what extent does this support the hypothesis that bus accidents are a frequent, the main, the only cause of broken legs? How much of the accident can be attributed to the elderly lady (did she jay walk?), the driver, poor lighting, fog, slippery road conditions, mechanical failure, another driver who caused the bus driver to swerve?

Attributing an outcome to one antecedent has been labeled 'single cause attribution' [59]. This is most often exemplified by what we call the 'individual perspective' in the previous section. One picks a case of PBD, searches for some event deemed an appropriate insult, and attributes causal properties to this event.

The errors of single cause attribution are also be made by academicians and investigators. The following are examples.

A popular textbook of neonatal neurology places the content dealing with WMD causation in a chapter labeled 'Hypoxic-Ischemic Encephalopathy: Neuropathology and Pathogenesis'. The author tips his hat to other possible etiologies, but makes abundantly clear that, in his eyes, his placement of the material is appropriate.

Hypoxia-ischemia (oxygen-glucose deprivation) causes brain damage in the laboratory. So do excitotoxins and inflammogens. Why choose hypoxia-ischemia as THE single cause, especially when this position is NOT supported by studies of humans?

Reports of clinical trials of head cooling for the neonatal disorder characterized by obtundation and brainstem dysfunction labeled the disorder hypoxic-ischemic encephalopathy. Sometimes this disorder has no obvious antecedent. Other times, epidemiologic studies show that it is associated with fetal/maternal inflammation. The disorder's label reflects the simplistic thinking that the existence of the disorder means that there must have been unseen/undocumented hypoxia-ischemia. Plaintiffs' attorneys tell the jury that the doctors caring for the unresponsive baby diagnosed her condition as hypoxic-ischemic encephalopathy, documenting that the obstetrician caused this child's damaged condition. And sometimes these attorneys win. 
Why cannot we attach the name 'newborn encephalopathy' to neonatal unresponsiveness accompanied by brainstem dysfunction and/or seizures? Doing so would avoid the fallacy of single cause attribution.

Extrapolating from the observation that ischemia causes brain damage in the laboratory to the belief that hypoxia-ischemia is the single cause of PBD in humans invokes both the misconception possibility to fact and this misconception (single cause attribution). The interrelatedness of the misconceptions needs to be kept in mind when either one misconception is identified. Might another unstated misconception have been invoked?

Despite early [21] and widespread [60] recognition that all diseases have multiple causes, the concept of single-cause attribution appears to be widely accepted. We often see publications that include lists of cases and their putative causes, without showing any data on controls. It even made its way into the language of imaging colleagues who describe what they identify on ultrasound pictures as 'ischemic lesions' [see 61 for discussion and critique of this concept]. We raise the possibility that names of entities/lesions that imply a known causation when the evidence is not convincing can impede progress identifying the myriad contributors to PBD causation.

Although we have attempted to avoid offending anyone by not identifying papers that exemplified one of the misconceptions we address, we consider it appropriate to use our own work to illustrate how single-cause attribution was applied to a group of preterm children with cerebral palsy, the clinical neurodevelopmental symptom strongly associated with WMD [62]. The presence of certain characteristics in these individual children's histories (e.g. cord prolapse) was assumed a 'definite explanation' of the child's cerebral palsy, that of others (such as 'severe postnatal asphyxia') a 'possible explanation'. Interestingly, this way of attributing single causes yielded $32 \%$ explained, $32 \%$ possibly explained, and $36 \%$ not explained cases. This result is not very different from what would be expected if one of three possible outcomes had been attributed by chance ( 1 of $3=33.3 \%$ ).

A sophisticated extension of the single cause attribution concept is the etiological pathway concept $[63,64]$. This theory suggests that in individual infants, several different (but distinct) pathways can culminate in brain damage. The clear advantage of this concept is that not all cases of PBD are assumed equal with regard to causal mechanisms. A much more realistic way is to look at disease causation from the probabilistic perspective, which holds that 'the presence of $\mathrm{X}$ increases the likelihood of the occurrence of Y' (see 'Determinism vs. Probabilism' above). However, this concept may be of limited use in individual patients. We advise against offering numbers and percents to parents, either in matters of causation or prognosis.

Nevertheless, the probabilistic approach offers enormous advantages in etiologic research and causal inference. Moreover, it paves the way for what is now considered the standard of sophisticated etiologic research, i.e. elaborate multivariable data analysis. Only this approach allows for the modeling of a multicausal network, the closest theoretical framework for the study of the multietiologic natural history of diseases.

\section{Generalization}

Sometimes, we are sure we have found the cause of PBD in a single individual newborn. A catastrophic situation such as placental abruption is often considered highly suggestive of being the initiator of perfusion disturbances and associated energy failure, leading to PBD [65]. It is eminently conceivable that even in such a supposedly clear-cut situation, the origin of the observed brain damage might actually be what led to the catastrophe, e.g. infection/inflammation [66-68], not the catastrophe itself (placental abruption). Thus, we consider it reasonable to argue that the mere observation of a rather suggestive co-occurrence (see 'Co-Occurrence in Individuals vs. Association in Populations' above) of a plausible cause (here: abruption) and effect (here: PBD) in single clinical instances should not trigger the clinician's, judge's, lawyer's, or jury member's generalization that in all babies with placental abruption any co-occurring PBD must be due to the abruption.

\section{Unstated Causal Inferences}

Amniotic fluid embolism results in profound and prolonged maternal hypotension, which interferes with the placenta's ability to provide the fetus with oxygen. If the mother's circulation is not improved, she will die. If the fetus cannot be delivered in time, the fetus, too, will die. If the fetus is delivered alive, however, brain damage may have occurred.

In light of this scenario, it seems eminently reasonable to invoke the 'continuum of casualty' hypothesis, which as applied to the brain, states that the same insult, if severe kills, but if less severe kills not the entire individual, but only the most vulnerable cells, assumed to be neurons [69].

Although on one level this hypothesis is plausible, it does not apply to less catastrophic situations, for example, when the term infant with newborn encephalopathy is 
presumed to have suffered an intrapartum insult despite the mother having no documented physiologic disturbance. The inference that low blood pressure in a sick infant born months before term who is presumed to have impaired cerebral blood flow regulation leads to WMD can be viewed as another example of inappropriately applying the continuum of casualty hypothesis. The inferential error tends to be made by those who are not aware that they are invoking the hypothesis [70]. We encourage the explicit statement of all causal inferences.

\section{Unstated Assumption that What Might Be}

Heterogeneous Is Homogeneous

In $\mathrm{PBD}$, this inferential error is exemplified by papers that list grade III/IV intraventricular hemorrhage (IVH) as an outcome or a covariate [71]. In such situations, a hemorrhage that fills the lateral ventricle (IVH) is equated with a large echodensity adjoining the lateral ventricle. An extension of this assumption is the assumption that WMD and IVH are etiologically equivalent. We are not arguing against the possibility that IVH is an antecedent or correlate of WMD damage. Rather, they just are not identical, nor should each be presumed to have exactly the same risk profile as the other.

Use of the entity called 'grade III/IV IVH' assumes that grade III IVH is the same as grade IV in terms of etiology, pathophysiology or consequences, depending on the setting in which it is used. Since what is called grade IV IVH might not be primarily a hemorrhage, continued use of the term perpetuates many errors and promotes inferential errors [72].

When the borders of the lateral ventricle are lost and the ventricle contents cannot be distinguished from the surrounding echodense white matter, even highly competent sonologists might not be able to tell where is the boundary between hemocephalus and adjacent normal or damaged white matter. This quandary is real. Limiting use of the 'grade III/IV IVH' to these situations is inappropriate. Failure to recognize the misconception leads to inferential errors.

Our main point is that progress in our thinking about causation will not come until we define exposures and characteristics as homogeneously as possible and seek the antecedents of the most homogeneous outcome possible.

\section{Failure to Consider Alternative Explanations}

In 1650, Oliver Cromwell wrote, 'I beseech you, in the bowels of Christ, think it possible you may be mistaken' [73]. The last seven words of this quote constitute the
Cromwellian challenge taught to students of epidemiology. Unfortunately, some see a paper or a table of data that fits their favorite hypothesis and accept it without any reservation. We suggest that all findings and publications be interpreted with the Cromwellian challenge in mind.

\section{Conclusions}

Research in the field of PBD is either observational or experimental [for an overview, see 4]. By definition, observational studies can only study association, but never prove causation. Experimental studies can show that an exposure 'can' produce an outcome, but this is never a 'must' outside the experimental world. Apparently, causal inference needs support from both observation and experiment, from both epidemiology and laboratory research [5]. Thus, we propose that the more of the following criteria are fulfilled, the stronger the support for the contention that some risk factor for PBD might be a 'causal' factor:

- the factor precedes PBD (however, even if it does, how do we distinguish 'post hoc' from 'propter hoc'?);

- the factor can produce PBD in the experimental setting (still, a clear definition of 'can' should be sought in future causality research);

- it is (statistically) associated with PBD in (well-powered) observational studies;

- its absence from populations reduces the prevalence of PBD compared to populations with the factor present, e.g. in clinical trials [5].

We do not suggest that our discussion and proposed criteria solve any theoretical issue in causation/causality research. Rather, we hope they can serve as guiding lights for clinicians and public health workers in the dark wilderness of causal inference and can contribute to fruitful research in this area, designed to reduce the individual and societal burden of PBD.

\section{Acknowledgements}

The authors appreciate Professor Uwe Meixner's comments on their manuscript. While working on the paper, they were supported by grants from the National Institutes of Health (NS040069) and the Wilhelm Hirte Stiftung, Hannover, Germany. 
1 De Vries LS, Groenendaal F: Neuroimaging in the preterm infant. Ment Retard Dev Disabil Res Rev 2002;8:273-280.

2 Ferriero DM: Neonatal brain injury. N Engl J Med 2004;351:1985-1995.

3 Rutherford M, Ward P, Allsop J, Malamatentiou C, Counsell S: Magnetic resonance imaging in neonatal encephalopathy. Early Hum Dev 2005;81:13-25.

4 Hagberg H, Peebles D, Mallard C: Models of white matter injury: comparison of infectious, hypoxic-ischemic, and excitotoxic insults. Ment Retard Dev Disabil Res Rev 2002; 8:30-38.

5 Dammann O, Leviton A: Inflammatory brain damage in preterm newborns - dry numbers, wet lab, and causal inference. Early Hum Dev 2004;79:1-15.

6 Rees S, Inder T: Fetal and neonatal origins of altered brain development. Early Hum Dev 2005;81:753-761.

7 Rothman KJ, Greenland S: Modern Epidemiology, ed 2. Philadelphia, Lippincott-Raven, 1998.

8 Dawid AP: Probability, causality and the empirical world: a Bayes-de Finetti-PopperBorel synthesis. Stat Sci 2004;19:44-57.

9 Buck C: Popper's philosophy for epidemiologists. Int J Epidemiol 1975;4:159-168.

10 Maclure M: Popperian refutation in epidemiology. Am J Epidemiol 1985;121:343350 .

11 Greenland S: Induction versus Popper: substance versus semantics. Int J Epidemiol 1998;27:543-548.

12 Sosa E, Tooley M (eds): Causation. Oxford, Oxford University Press, 1993.

13 Meixner U: Theorie der Kausalität. Paderborn, Mentis, 2001.

14 Hill AB: The environment and disease: association or causation? Proc R Soc Med 1965; 58:295-300.

15 Susser MW: Causal Thinking in the Health Sciences - Concepts and Strategies of Epidemiology. New York, Oxford University Press, 1973.

16 Susser M: What is a cause and how do we know one? A grammar for pragmatic epidemiology. Am J Epidemiol 1991;133:635648.

17 Parascandola M, Weed DL: Causation in epidemiology. J Epidemiol Community Health 2001;55:905-912.

18 Rothman KJ, Greenland S: Causation and causal inference; in Rothman KJ, Greenland S (eds): Modern Epidemiology. Philadelphia, Lippincott Williams \& Wilkins, 1998, pp 728.

19 Pearl J: Causality. Cambridge, Cambridge University Press, 2000.

20 Glymour C, Cooper GF (eds): Computation, Causation, and Discovery. Menlo Park/ Cambridge, AAAI Press/MIT Press, 1999.
21 Rothman KJ: Causes. Am J Epidemiol 1976; 104:87-92.

22 Boffetta P: Molecular epidemiology: a tool for understanding mechanisms of disease. Eur J Surg Suppl 2002:62-69.

23 Rorty R: Philosophy and Social Hope. London, Penguin, 1999, pp xvi-xxxii.

24 du Plessis AJ, Volpe JJ: Perinatal brain injury in the preterm and term newborn. Curr Opin Neurol 2002;15:151-157.

25 Rezaie P, Dean A: Periventricular leukomalacia, inflammation and white matter lesions within the developing nervous system. Neuropathology 2002;22:106-132.

26 Vannucci SJ, Hagberg H: Hypoxia-ischemia in the immature brain. J Exp Biol 2004;207: 3149-3154.

27 Dammann O, Leviton A: Role of the fetus in perinatal infection and neonatal brain damage. Curr Opin Pediatr 2000;12:99-104.

28 Kadhim H, Sebire G: Immune mechanisms in the pathogenesis of cerebral palsy: implication of proinflammatory cytokines and $\mathrm{T}$ lymphocytes. Eur J Paediatr Neurol 2002;6: 139-142.

29 Bracci R, Buonocore G: Chorioamnionitis: a risk factor for fetal and neonatal morbidity. Biol Neonate 2003;83:85-96.

30 Hagberg H, Wennerholm UB, Savman K: Sequelae of chorioamnionitis. Curr Opin Infect Dis 2002;15:301-306

31 Edwards AD: New approaches to brain injury in preterm infants. Dev Neurosci 2003; 24:352-354.

32 Garnier Y, Coumans AB, Jensen A, Hasaart $\mathrm{TH}$, Berger R: Infection-related perinatal brain injury: the pathogenic role of impaired fetal cardiovascular control. J Soc Gynecol Investig 2003;10:450-459.

33 Dammann O, Leviton A: Brain damage in preterm newborns: might enhancement of developmentally-regulated endogenous protection open a door for prevention? Pediatrics 1999; 104:541-550.

34 Leviton A, Blair E, Dammann O, Allred EN: The wealth of information conveyed by gestational age. J Pediatr 2005;146:123-127.

35 Leviton A, Paneth N: White matter damage in preterm newborns - an epidemiologic perspective. Early Hum Dev 1990;24:1-22.

36 Hagberg H, Dammann O, Mallard C, Leviton A: Preconditioning and the developing brain. Semin Perinatol 2004;28:389-395.

37 Eklind S, Mallard C, Leverin AL, Gilland E, Blomgren K, Mattsby-Baltzer I, Hagberg H: Bacterial endotoxin sensitizes the immature brain to hypoxic - ischaemic injury. Eur J Neurosci 2001;13:1101-1106.

38 Dommergues MA, Patkai J, Renauld JC, Evrard P, Gressens P: Proinflammatory cytokines and interleukin-9 exacerbate excitotoxic lesions of the newborn murine neopallium. Ann Neurol 2000;47:54-63.
39 Dammann O, Allred EN, Kuban KCK, Van Marter LJ, Pagano M, Leviton A, for the Developmental Epidemiology Network: Hypocarbia during the first 24 postnatal hours and periventricular echolucencies in newborns $<28$ weeks gestation. Pediatr Res 2001; 49:388-393.

40 Banker BQ, Larroche JC: Periventricular leukomalacia of infancy. Arch Neurol 1962; 7:386-410.

41 Levine S: Anoxic-ischemic encephalopathy in rats. Am J Pathol 1960;36:1-17.

42 Levy DE, Brierley JB, Silverman DG, Plum F: Brief hypoxia-ischemia initially damages cerebral neurons. Arch Neurol 1975;32:450456.

43 Rice J, Vannucci RC, Brierley JB: The influence of immaturity on hypoxic-ischemic brain damage in the rat. Ann Neurol 1981;9: 131-141.

44 Tyszczuk L, Meek J, Elwell C, Wyatt JS: Cerebral blood flow is independent of mean arterial blood pressure in preterm infants undergoing intensive care. Pediatrics 1998;102: 337-341.

45 Hagberg H, Bona E, Gilland E, Puka-Sundvall $M$ : Hypoxia-ischaemia model in the $7-$ day-old rat: possibilities and shortcomings. Acta Paediatr Suppl 1997;422:85-88.

46 Neu J: The 'myth' of asphyxia and hypoxiaischemia as primary causes of necrotizing enterocolitis. Biol Neonate 2005;87:97-98.

47 Greisen G, Borch K: White matter injury in the preterm neonate: the role of perfusion. Dev Neurosci 2001;23:209-212.

48 Eells E: Probabilistic Causality. Cambridge, Cambridge University Press, 1991.

49 Hitchcock C: A generalized probabilistic theory of causal relevance. Synthese 1993;97: 335-364.

50 Gallo RC, Montagnier L: The discovery of $\mathrm{HIV}$ as the cause of AIDS. N Engl J Med 2003;349:2283-2285.

51 Beattie T, Rowland-Jones S, Kaul R: HIV-1 and AIDS: what are protective immune responses? J HIV Ther 2002;7:35-39.

52 Batton DG, Kirtley X, Swails T: Unexpected versus anticipated cystic periventricular leukomalacia. Am J Perinatol 2003;20:33-40.

53 Evidence-Based Medicine Working Group: Evidence-based medicine. A new approach to teaching the practice of medicine. JAMA 1993;268:2440-2445.

54 Dammann O: Evidence-based child neurology. Dev Med Child Neurol 2006;48:622624

55 Dammann O, Allred EN, Kuban KC, Van Marter LJ, Pagano M, Sanocka U, Leviton A: Systemic hypotension and white-matter damage in preterm infants. Dev Med Child Neurol 2002;44:82-90.

56 Hofer T, Przyrembel H, Verleger S: New evidence for the theory of the stork. Paediatr Perinat Epidemiol 2004;18:88-92. 
57 Arnett HA, Mason J, Marino M, Suzuki K, Matsushima GK, Ting JP: TNF alpha promotes proliferation of oligodendrocyte progenitors and remyelination. Nat Neurosci 2001;4:1116-1122.

58 Gupta S: A decision between life and death during TNF-alpha-induced signaling. J Clin Immunol 2002;22:185-194.

59 Leviton A: Single-cause attribution. Dev Med Child Neurol 1987;29:805-807.

60 Barnetche T, Gourraud PA, Cambon-Thomsen A: Strategies in analysis of the genetic component of multifactorial diseases; biostatistical aspects. Transpl Immunol 2005; 14:255-266.

61 Kuban KC: White-matter disease of prematurity, periventricular leukomalacia, and ischemic lesions. Dev Med Child Neurol 1998;40:571-573.

62 Veelken N, Schopf M, Dammann O, Schulte FJ: Etiological classification of cerebral palsy in very low birthweight infants. Neuropediatrics 1993;24:74-76.
63 Blair E, Stanley F: Aetiological pathways to spastic cerebral palsy. Paediatr Perinat Epidemiol 1993;7:302-317.

64 Blair E, Stanley F: When can cerebral palsy be prevented? The generation of causal hypotheses by multivariate analysis of a casecontrol study. Paediatr Perinat Epidemiol 1993;7:272-301.

65 Gibbs JM, Weindling AM: Neonatal intracranial lesions following placental abruption. Eur J Pediatr 1994;153:195-197.

66 Darby MJ, Caritis SN, Shen-Schwarz S: Placental abruption in the preterm gestation: an association with chorioamnionitis. Obstet Gynecol 1989;74:88-92.

67 Kramer MS, Usher RH, Pollack R, Boyd M, Usher S: Etiologic determinants of abruptio placentae. Obstet Gynecol 1997;89:221-226.
68 Rana A, Sawhney H, Gopalan S, Panigrahi D, Nijhawan R: Abruptio placentae and chorioamnionitis-microbiological and histologic correlation. Acta Obstet Gynecol Scand 1999;78:363-366.

69 Lilienfeld AM, Parkhurst E: A study of the association of factors of pregnancy and parturition with the development of cerebral palsy: preliminary report. Am J Hyg 1951;53: 262-282.

70 Ounsted M: Causes, continua and other concepts. I. The 'continuum of reproductive casualty'. Paediatr Perinat Epidemiol 1987;1: 4-7.

71 Papile LA, Burstein J, Burstein R, Koffler H: Incidence and evolution of subependymal and intraventricular hemorrhage: a study of infants with birth weights less than 1,500 gm. J Pediatr 1978;92:529-534.

72 Paneth N: Classifying brain damage in preterms. J Pediatr 1999;134:527-529.

73 The Oxford Dictionary of Quotations. Oxford, Oxford University Press, 1979, p 169. 